ves to eliminate unreasonable persons; i.é., those who are to be considerad intelectually, professionall, or morally sub-standard in international trade. "M. Will, ob. cit. p. 219, in fine.

24 Durante a discussão sobre as características que deveria ter a pessoa razoável, a reasonable person, a França suge riu a figura tradicional em seu direito, o bom pai de familia, adaptado às circunstâncias, "le bon père de famille devenu commerçant international ", e a URSR, a do comerciante dedicado ao comercio internacional, " merchant engaged in intemational conmerce.

25 A esse respeito ver LARENZ, Karl, in Derecho Justo, pp. 114 e ss.

$26 \mathrm{E}$ precisamente a finalidade que determina a concep ção da obrigação como um processo, ensina Clóvis

Couto e Silva, in Obrigação como Processo, p. 10.

27 Há quem veja a obrigação como uma estrutura (Gefuege) em sentido hegeliano, como é o caso de Larenz; "Gutros, veem a obrigação como uma forma propria, uma Gestalt, isto é, nâo como uma soma de elementos que "Zusamo ser isolados, e sim como conjuntos, Zusamnhar , que possuem uma solidariedade incana e tem las prophas, de modo que a forma de ser de cada parte, depende da estrutura do conjunto. A esse respeito, manilesta-se ZEPOS, Panajlotis: "Will man nun das man es als "gin sich ör man es als eine in sich organisierte Ganzheit von fechen we Sume we dumme oder die mechanische Anhäurung der dahingehorenden Elemente, sondern etwas mehr, eine eigentlicher Komplex von Rechten und Pflichten eigen Schuldverälnis hat indiser hing Gestaltqualitï" In AcP, 155, pp. 490 ss. "Zur einer Gestaltqualitit." In AcP, 155, pp. 490 e ss. "Zur einer 28 No original: "das Gebot der Rücksichtnahm

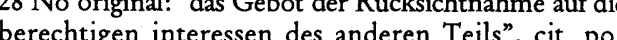
ALMEIDA COSTA, Mário Júlio de, In Direito das Obrigações, p. 81.

29 Artigo $7^{\circ}$ da Convenção: (1) In the interpretation of this Convention, his Convention, regard is to be had to its ine to application and the observance of good faith in intercation and

Bibliografia

I. Compêndios

Alvim, Agostinho. Da inexecução das obrigações e suas con seqüências. São Paulo: Saraiva, 1949.

Bianca, C. M. Bonell, M. J. Commentary on the International Sales Law: The 1980 Vienna Sales Convention. Milan, Giuffre The

Bulgarelli, Waldírio Contratos Mercantis, 4 ed São Paulo: Atlas, 1988.
Caetano, Marcelo Alves, José Carlos Moreira; Silva, Clóvis do Couto e; costa, Mário Júlio de Almeida. Estudos de Direito Civil Brasileiro e Português. (I Jornada luso-brasCo ca dir to civil). São Paulo: RT, 1980

Costa, Mário Júlio de Almeida. Direito das Obrigações, 4.ed. Almedina, 1984, p. 230 a 259.

Gonzáles, Aurora Gonzáles. La Resolucion como efecto del incumplimiento en las obligaciones bilaterales. 1. ed. Barceona: Bosch, 1987. (Monografia)

Larenz, Karl. Derecho de Obligaciones. Editorial Revista de Derecho Privado, Tomo I, Madrid: 1958.

Derecho Justo. Fundamentos de Ética Jurídica. Madrid Civitas S/A, 1985. (Monografia)

Miranda, Pontes de. Tratado de Direito Privado, v. 38 Borsói, 1962, p. 331 a 348.

Represas, Felix Trigo; Stiglitz, Rubén S.; e outros. Con

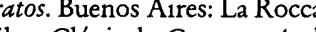

Silva, Clóvis do Couto e. A obrigasãa como processo. São aulo: José Bushatsky, 1976

Wncitral Wiener. Ubereinkommen über internationale Warenkaufvertrage, vom. Il, Rolf Herber, April, 1980. Weacker, Franz. El Pring Madrid: Civitas, 1982.

ill, M. Commentary on the International Sales Law Art. 25 - Fundamental Breach. Milan: Giuffrè 1987.

II. Periódicos

Bianca, C. Massimo. La Nozione di Buona Fede quale regola di comportamento contrattuale. Riv. di Dir. Civ. n. 3, 1983, pp. 206/216.

n. . 94.321 ess.

Caemmerer, Ernst von. Probleme des Haage 2-3. AeP 1978, 131 (wesentliche Vernags, 178, Heft . AeP 1978, P.

Vols. 15A (condition) e 93, $\$ 342$

Fadlallah, Ibrahim. Projeto de Convenção sobre a Vend Prove Tribunais, 630, abril 1988, (Prof. na Univ. de Dijon e Paris II).

Kahn, Philippe. La Convention de Vienne du 11 abril 1980 sur les contrats de vente Vienne du 11 abri marchandises, Revue Intern de Droit Comparé, 33, 1981, p. $951-986$.

p. $951-986$.

Schlechtriem, Peter. Einheitliches UN-Kaufrecht. Juristen Zeitung. 43. Jahrgang 18. November 1988, p. 1037-1043. Tunc, André. Padrões Jurídicos e Unificação do Direito. Revista de Consultoria Geral do Estado, vol.IV, n. 9, 1974. ass aspects juridiques de l'economiept contratue Les aspects juridiques de leconomie concer
contractuelle. Rev. Trim. Dr. Civ. 1964, p. 5-48. contractuelle. Rev. Trim. Dr. Civ. 1964, p. 5-48. Auffassung des Schuldverhältnisses. Archiv civil Praxis. AeP Band 155. p. 486 .

\title{
A compensação de tributos no Direito brasileiro - parte geral
}

Franz August Gernot Lippert

Professor Adjunto da Faculdade de Direito da UFRGS

SÚMARIO

1. A Compensação no Direito Romano e Medieval; 2. A Compensação no Direito Moderno; 3. A Compensação no Direito Tributário Moderno; 4. A Compensação no Direito Tributário Brasileiro; 5. Em Conclusão; 6. Observações Finais; 7. Bibliografia.

\section{Abstract}

La législation fiscale au Brésil a resisté pendant long temps à admettre la compensation à l'égard des impôts.

Ce ne fut qu'en 1991, que la Loi Fédérale $n^{\circ} 8.383$ a introduit effetivement la com pensation des impôts fédéraux, mais ençore d'une façon trop restreinte qu'il est indispensable de la modifier en élargissant son champ d'application pour atteindre une vraie justice fiscale.

\section{A compensação no Direito Romano e Medieval}

Compensar significa estabelecer o equilíbrio, contrabalançar, contrapesar, pesar 2 créditos, um de A contra um de B e outro de B contra o de A.

"Compensam-se crédito e dívida.

Um vai a um prato o outro ao outro prato da balança"1

"Le mot compensation, de prendere cum, éveille l'idée d'une pesée, d' une balance. La balance des sommes que deux personne se doivent réciproquement." 2

Apesar da comprovada utilidade jurídica do instituto da compensação surge a mesma apenas, bastante tarde no Direito Romano, desconhecendo-a o direito romano antigo, em decorrência da adoção pelo seu direito processual do "princípio da unicidade da questão" ou, em outras palavras, "a cada questão o seu processo."

Cada crédito existia independentemente, sem que outro crédito pudesse compensá-lo ressalvada a hipótese da deductio, que era oponível aos banqueiros e aos emptores bonorum, figura do direito falimentar. Apenas a partir de Marco Aurélio admitiu-se a compensação como modo especial de extinção de obrigações, até onde essas se equivaliam, entre pessoas que eram, ao mesmo tempo, devedora e credora uma da outra mas, apenas, a título de exceptio doli, pois passou-se a considerar dolo pedir o que imediatamente teria que ser restituído: Dolus facit, qui petit quod redditurùs est. (Paulo, $\mathrm{L}$. $173,3, \mathrm{D}$, de diversis regulis iuris antiqui, 50 $17)^{3}$.

Justiniano, regulando a compensação em novas bases, ampliando-a (Cód. Liv. IV, Tit. 31 , pág. 14), deu ao instituto, basicamente suas características atuais, distinguindo:

1. A compensação legal, ex lege, ipso jure ou automática, que se opera em decorrência da constituição do suporte fático previsto na lei, extinguindo-se as obrigações até onde se compensarem;

2. A compensação judicial, que consiste no acolhimento pelo juiz da alegação do réu da existência de contracrédito, hoje feita na reconvenção ou nos embargos, alegação que se constitui em exercício de direito formativo extintivo; e 
3. A compensação negocial, verdadeiro negócio jurídico, contrato de compensação, regido pelos princípios gerais atinentes, por exemplo, a nulidade, a anulabilidade ou a rescisão.

Criado o instituto, passou o mesmo a ter um largo e crescente uso, em decorrência de sua grande utilidade, seu verdadeiro fundamento, como ensinou de maneira simples e contundente, Cino de Pistoia, quando escreveu: Melius est non solvere quam solutum repetere.

As Ordenações Afonsinas (Livro IV, Título 72, pr.) referem-se à compensação da seguinte maneira:

"Compensaçom quer tanto dizer com desconto d'huã divida a outra. E fo introduzida per direito com justa razom de igualdade, porque mais razoada cousa he nom pagar homem o que nom deve, se lhe outro tanto he devudo, ca pagallo, e despois repetillo, com cousa nom devuda. (No $\$ 1^{\circ}$, aparecia o "com tanto que se alegue". 4

As Ordenações Manuelinas, (Livro IV, Título 56 pr.) e as Ordenações Filipinas (Livro IV, Título $78 \mathrm{p}$.) repetiram o texto das Ordenações Afonsinas a respeito.

\section{A compensação no Direito Moderno}

Constituindo-se a compensação num dos modos de extinção das obrigações, surgiram a respeito 3 (três) sistemas a saber

2.1. O Sistema francês, onde a compensação se opera, por influência direta da sistemática adotada por Justiniano, de pleno direito, automaticamente, nos termos do disposto no artigo 1290 do Código Civil Francês, nos seguintes termos:

"Art. 1290 - La compensation s'opère de plein droit par la seule force de la loi, même à l'insu des débiteurs, les deux dettes s'eteignent réciproquement, à l'instant òu

eles se trouvent exister à la fois, jusqúà concurrence de leurs quotités respectives".

2.2. O sistema germânico:

2.2.1. A compensação legal e judicial eram alheias ao direito germânico, onde era admitida, apenas, a compensação por negócio jurídi$\mathrm{co}$, através do contrato de compensação.

2.2.2. Atualmente, admite o direito alemão, nos termos constantes dos $\$ 387$ a 396 do B.G.B., as 3 (três) formas de compensação já referidas: a legal, a judicial e a negocial, exigindo, entretanto, quanto à primeira, nos termos do disposto no $\ 388$ B.G.B., expressa manifestação do credor-devedor compensante, através de emissão de declaração receptícia de vontade, exercício de direito formativo extintivo.

2.3. No sistema inglês a compensação se efetiva, apenas, por ato judicial ou negocial ${ }^{5}$.

\subsection{O sistema brasileiro:}

A concepção brasileira da compensação legal encontra-se regulada nos artigos 1.009 e 1.010 do Código Civil, tendo, aparentemente, o nosso sistema jurídico adotado o sistema francês da compensação ex lege, legal, de "pleno direito", ou automática, conforme a opinião da quase totalidade dos juristas nacionais; tendo rompido, assim, com a tradição luso-brasileira, que exigia a alegação. Esta corrente, entretanto, foi combatida por Pontes de Miranda ${ }^{6}$, eis que a alegação da compensação, no direito brasileiro para este autor, constituiuse em elemento integrativo de seu suporte fático.

“A alegação não é o exercício de pretensão a compensar, é exercício de direito formativo extintivo, de direito formativo à compensação; portanto, o suporte fático da compensação a que, faltava esse elemento, se perfaz, automaticamente"

Não há, entretanto, dúvida dos autores a respeito da necessidade da alegação, quanto à compensação judicial, nos termos do disposto no artigo 745 do Código de Processo Civil.
4.1. Os Pressupostos da Compensação )ireito Brasileiro

endo a compensação um meio especial xtinção de obrigações, até onde se equi$\mathrm{n}$, entre pessoas, que são ao mesmo temevedores e credores, uma da outra, consse serem nos termos da legislação brasi, os seguintes os seus pressupostos:

4.1.1. A reciprocidade das obrigações nomento da compensação, nos termos ırt. 1.009 do Código Civil Brasileiro, renseitigkeit do direito alemão); existênle 2 (dois) ou mais créditos contrapos"A" é credor de " $B$ " e " $B$ " é credor de eis que a extinção das obrigações ope: pelo "encontro de créditos recíprocos" e as mesmas partes.

:.4.1.2. A compensabilidade das dívidas :ichartigkeit), sua mesmeidade, fungilade, igualdade, ou homogeneidade, nos Ios dos arts. 1.010 e 1.011 do Código Civil ileiro, referente sempre à natureza das preses devidas e não à sua causa jurídica. Não é iente que cada um dos créditos cuja comação se pretende seja "em si" fungível, é ssário, entretanto, que os créditos a serem pensados sejam "entre eles" fungíveis.

4 compensabilidade, a mesmeidade, a ribilidade ou igualdade, que se exige aos itos a serem compensados, não é a igualz quantitativa: basta a homogeneidade ou ldade qualitativa, admitindo-se, consentemente, a compensação parcial.

$\supset$ conceito de compensabilidade foi, em parte, estruturado pela jurisprudência.

2.4.1.3. A certeza e liquidez das dívidas, termos do disposto nos arts. 1.010 e 1.012 ligo Civil Brasileiro; a "certeza" refereexistência da dívida; a liquidez concerne uantum da dívida; essa deve ser determia quanto a seu objeto. A dívida não deile ser líquida, se precisa de simples opeo matemática para sua fixação como, por exemplo, do cálculo dos juros legais ou da correção monetária. - Se o crédito certo significa que ele é plenamente eficaz.

2.4.1.4. A exigibilidade das prestações; as dívidas, nos termos do disposto no artigo 1.010 do Código Civil, devem estar vencidas. Somente dívidas vencidas podem ser compensadas.

O artigo 170 do Código Tributário, entretanto, permite a compensação de crédito vencido com créditos vincendos. - As dívidas prescritas também são compensáveis, se a compensabilidade ocorreu antes da prescrição.

2.4.1.5. O ato de alegação da compensação pelo credor-devedor, que é exercício de direito formativo extintivo no direito brasileiro, conforme ensinamento de Pontes de

Miranda, já anteriormente mencionado.

\section{A compensação no Direito Tributário moderno}

3.1. A doutrina

3.1.1. O Professor Alcides Jorge Costa examinando a literatura européia da primeira metade deste século a respeito da compensação no direito tributário, em princípio conclui que em geral ela é admitida em maior ou menor extensão e poucas vezes vetada, mas sempre com tendência a tornar-se menos ampla que no direito privado, indicando a respeito:

1. Henri de Page, Traité Elementaire de Droit Civil Belge, Ed. Bruxelas, 1950, Etablissements Bruylant Emile, $2^{2}$ ed. pág. 619

2. Ernst Blumenstein, "Sistema di Diritto delle Imposte”, Dott. Antonio Guiffré, Milano, pág. 249 e 439;

3. Giorgio Tesero, "Principi di Diritto Tributário, Ed. Dott Luigi Monci, Bari 1938, pág. 496; $\mathrm{e}$

4. Antonio Berliri, "Principi di Diritto Tributário”, Ed. Dott. A. Giuffré, Milano 1957, vol. II, pr. 328 
Conclui o Professor Alcides Jorge Costa que:

1. Henri de Page, quanto à Bélgica, informa que não se admite a compensação, porque $o$ interesse geral exige que a arrecadação de impostos seja sempre assegurada, pois dela depende a vida diária do Estado.

2. Ernst Blumenstein, quanto ao direito suíço entende que à parte do silêncio da lei, a inexistência da compensação, envolvendo créditos tributários, deriva da natureza juspublicística do crédito do imposto, sendo o dever tributário um dever cívico do devedor do imposto, não podendo o mesmo liberar-se, reportando-se a relações jurídicas patrimoniais de qualquer natureza com o ente público.

3. Giorgio Tesoro, quanto ao direito italiano, produz uma larga argumentação para demonstrar que não deve haver compensação quando está em jogo um crédito tributário, pois o interesse geral existe que seja assegurada a arrecadação rápida dos tributos por serem distintas a natureza do direito do Estado, que é um crédito publicístico, e a natureza do direito do particular, que corresponde a um crédito de natureza privatística.

4. Antonio Berliri, entende, quanto ao direito tributário italiano em especial e quanto ao direito tributário em geral, ser a compensação uma forma instantânea de extinção da obrigação, economicamente equivalente ao pagamento e (sendo esta conclusão extremamente importante) "não existir diferença estrutura entre obrigações de direito público e de direito privado".

Conclui Berliri que "o problema da admissibilidade ou não da compensação deve ser examinado e resolvido não com base em princípios mais ou menos discutíveis, afirmados aprioristicamente, mas com base em normas do código coordenadas com as que regulam os pagamentos e a arrecadação dos entes públicos".

3.2. Regras Jurídicas Atinentes à Compensação Tributária
3.2.1. A mais antiga norma jurídica atinente à compensação que encontrei é a seguinte: "Compensationi fiscali ita demum locum esse, si eadem statio quid debeat quae petit. Adque hoc juris propter confutionem diversorum officiorum tenaciter servandum est. L. 45, $5^{\circ}$, Dig. De Jure Fisci."

3.2.2. O grande Teixeira de Freitas, "Projeto", art. 1.169 , redigiu a respeito da compensação do crédito tributário um texto, que resultou no artigo 823 do Código Civil Argentino, nos seguintes termos:

"823. Las deudas y créditos entre particulares y el Estado no son compensables en los casos siguientes:

$1^{\circ} \mathrm{Si}$ las deudas de los particulares proveniesen de remates de cosas del Estado, o de rentas fiscales, o si proviniesen de contribuciones directas o indirectas, o de alcance de otros pagos que deban hacerse en las aduanas, como derechos de almacenaje, depósito, etcétera.

$2^{\circ} \mathrm{Si}$ las deudas y los créditos no fuesen del mismo departamento o ministerio.

$3^{\circ}$ En el caso que los créditos de los particulares se hallen comprendidos en la consolidación de los créditos contra el Estado, que hubiese ordenado la ley."

3.2.3. Diferente, entretanto, o regramento quanto à compensação de crédito particular cum um crédito público no Código Civil Alemão cujo $\$ 395$ dispõe:

"Contra um crédito da Federação ou de um Estado federado, assim como contra um crédito de um município ou de uma outra união comunal, só é admissível a compensação quando a prestação tiver de realizar-se à mesma caixa pela qual o crédito do compensante deve ser pago" 9

A palavra caixa = "Kasse" deve ser entendida, de acordo com a doutrina e jurisprudência alemã, como o órgão do respetivo poder público, que efetivamente receberia a respectiva quantia, se não houvesse compensação. 10

3.2.4. No dia $1^{\circ}$ de janeiro de 1977 , entrou em vigor o atual Código Tributário Nacional mão (Abgabenordnung) cujo $\$ 226$ regul seus 4 (quatro) incisos a compensação de litos tributários naquele país, nos seguin:ermos:

“(1) Para a compensação com pretensões orrentes de uma relação de débito de imto, bem como para a compensação contra $s$ pretensões, aplicam-se, no que couber, os ceitos do Direito Civil, salvo disposições contrário.

(2) Não é possível compensar com pretens decorrentes da relação de débito de imto, quando elas tenham sido extintas pela scrição ou pelo decurso de um prazo de clusão.

(3) Os contribuintes somente podem comısar contra pretensões decorrentes da rela, de débito de imposto pretensões não litigis ou insuscetíveis de impugnação.

(4) Para os efeitos da compensação, consia-se credor ou devedor de uma pretensão corrente da relação de débito de imposto a ssoa jurídica que administra o imposto" 11 Examinando-se o texto legal alemão consamos o seguinte:

1. Quanto à compensação legal tributária licam-se, salvo expressa disposição em conrio as normas do direito civil. (Ocorreu a blicização destas)

2. Não se admite a compensação, se houve escrição ou preclusão de um dos créditos.

3. O contribuinte poderá compensar, ape$s$, crédito líquido e certo $=$ crédito plena ente eficaz.

4. O disposto no $\$ 226$ é aplicável tanto ao vedor do imposto quanto como ao credo , imposto.

5. A compensação é uma extinção recíprode 2 créditos homogêneos, em decorrência : manifestação de vontade de uma das partes. 6. A exigência da "identidade de caixa" ou Sassenidentität”, prevista no $\$ 395$ do B.G.B. anteriormente referida, não foi alterada.
4. A Compensação no direito

tributário Brasileiro

4.1. Dispõe a respeito o artigo 1.017 do Código Civil Brasileiro:

"As dívidas fiscais da União, dos Estados e dos Municípios também não podem ser objeto de compensação, exceto nos casos de encontro entre a administração e o devedor, autorizados nas leis e regulamentos da Fazenda."

Merecem atenção as restrições e limitações ao uso da compensação, criadas pela legislação.

4.2. O "Anteprojeto" do mestre Rubens Gomes de Souza previa no seu artigo 184, III, expressamente, a extinção do Tributo através da compensação, dedicando ao instituto, ainda, os artigos 208 e 209.

Os dispositivos do Anteprojeto permitiriam a compensação tributária desde que:

1. admitida por disposição expressa da lei tributária;

2. sendo os créditos "de qualquer origem" vencidos, líquidos e certos;

3. contra pessoa jurídica a cuja competência pertencesse o tributo, adotando, conseqüentemente, o sistema de "identidade de caixa", (parecido com o sistema tributário da "Kassenidentität");

4. admitida por despacho da autoridade competente.

O artigo 209 admitiria a compensação legal a favor da Fazenda contra o contribuinte, decorrente de condenação judicial ou administrativa passada em julgada.

4.3. A "Comissão", entretanto, eliminou a compensação, entendendo existir "impedimento constitucional”, consubstanciado no princípio da universalidade do orçamento, consagrado pelo art. 73 da então Constituição Federal (1946), pois a unidade da tesouraria impediria a extinção dos débitos da Fazenda Pública por via da compensação, à margem das dotações orçamentárias votadas para a despesa. 
4.4. $O$ instituto da compensação finalmente veio constar do artigo 170 e $\$$ único do Código Tributário Nacional nos seguintes termos:

"Art. 170. A lei pode, nas condições e sob as garantias que estipular, ou cuja estipulação em cada caso atribuir à autoridade administrativa, autorizar a compensação de créditos tributários com créditos líquidos e certos, vencidos ou vincendos, ${ }^{12}$ do sujeito passivo contra a Fazenda Pública.

Parágrafo único. Sendo vincendo o crédito do sujeito passivo, a lei determinará, par os efeitos deste artigo, a apuração do seu montante, não podendo, porém, cominar redução maior que a correspondente ao juro de $1 \%$ (um por cento) ao mês pelo tempo a decorrer entre a data da compensação e a do vencimento".

Decorre do texto do art. 170 combinado com o artigo 91, I ambos do C.T.N. que somente a lei pode estabelecer a instituição ou extinção de tributo, e conseqüentemente, compensação, sendo uma das modalidades de extinção da obrigação tributária, ficará, no âmbito do direito fiscal, condicionada à existência de lei que expressamente a autorize ${ }^{13}$.

Em outras palavras, o artigo 170 do C.T.N, lei complementar, permite a compensação por lei ordinária de créditos vencidos e vincendos, líquidos e certos, nas condições e garantias que a lei ordinária estipular ou nas condições e garantias que a lei ordinária tenha autorizado a administração pública a estipular.

A compensação no direito tributário brasileiro dependerá sempre de expressa autorização legal, que deve estipular também as condições e garantias que serão exigidas pelo fisco para tanto, sem discricionaridade, face ao princípio da reserva legal ${ }^{14}$.

4.5. No direito tributário brasileiro encontramos a compensação tributária, exemplificativamente, em:

1. A lei $n^{\circ} 4.357 / 64$, conseqüentemente antérior à promulgação do C.T.N., que criou as Obrigações Reajustáveis do Tesouro Naci- onal - ORTN para o pagamento de qualquer tributo federal, como também as leis que criaram a Letra do Tesouro Nacional - LTN e o Bônus do Tesouro Nacional - BTN.

2. $\mathrm{O}$ artigo $161 \mathrm{da}$ anterior Constituição Federal, que admitia o pagamento do Imposto Territorial Rural com Títulos da Dívida Pública Federal.

3. As normas tributárias estaduais, como por exemplo, a Lei no 10.425 de 08 de dezembro de 1971 do Estado de São Paulo e o decreto $\mathrm{n}^{\circ} 21.899$, de 25 de julho de 1972 do Estado do Rio Grande do Sul, que permitiam a compensação, exegindo ambas as leis para a apresentação dos atinentes requerimentos da compensação a confissão irretratável do débito fiscal e a expressa renúncia a qualquer defesa ou recurso administrativo ou judicial, bem como a desistência dos já interpostos.

4. A compensação ocorria e ocorre, também, na área do Imposto de Renda, quando esse é retido na fonte, podendo ser compensado pelo contribuinte na sua declaração anual de rendimentos.

5. A compensação, quanto ao IPI e ICMS, está expressamente prevista na Constituição Federal em seus artigos $153, \mathbb{\$} 3^{\circ}, \Pi$ e e $155, \mathbb{S}$ $2^{\circ}$.

6. A lei $n^{\circ} 8.383 / 91$ regulou a compensa-

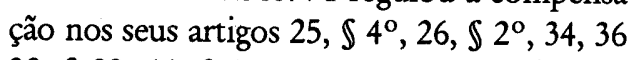
$38, \int 8^{\circ}, 66, \int 1^{\circ}$ a $3^{\circ}, 80$ e 81 , sendo o de maior alcance o artigo 66, cuja redação é a seguinte:

"Art. 66. Nos casos de pagamento indevido ou a maior de tributos e contribuições federais, inclusive previdenciárias, mesmo quando resultante de reforma, anulação, revogação ou rescisão de decisão condenatória, o contribuinte poderá efetuar a compensação desse valor no recolhimento de importância correspondente a períodos subseqüentes.

$\int 1^{\circ}$. A compensação só poderá ser efetuada entre tributos e contribuições da mesma espécie.

$\$ 2^{\circ}$. É facultado ao contribuinte optar pelo pedido de restituição. $3^{\circ}$. A compensação ou restituição será sada pelo valor do imposto ou contribuicorrigido monetariamente com base na ação da UFIR.

$\int 4^{\circ}$. O Departamento da Receita Federal nstituto Nacional de Seguro Social - INSS ¿dirão as instruções necessárias ao cumprito do disposto neste artigo".

Examinando-se o texto constata-se o seguin-

1. A compensação prevista no artigo 66 da $\iota^{\circ} 8.383 / 91$ somente pode ocorrer quanto butos e contribuiçõões federais;

2. Somente é admitida a compensação para tinção de dívidas tributárias correspondenI períodos subseqüentes à data do recolhiito, por erro ou da reforma, anulação, reação ou rescisão de decisão condenatória, inistrativa ou judicial.

Conseqüentemente, parece que não se ade a compensação para a extinção de dívidas utárias, que correspondam a períodos anores ao recolhimento por erro ou à data da rma, anulação, revogação ou rescisão da são condenatória, desconstituida, revogada, lada ou reformada, o que seria profundatte injusto.

Vittorio Cassone ${ }^{15}$ como outros estudiodo direito tributário, não concorda com interpretação por entender que a norma zce presumir que os tributos correspondena períodos anteriores sempre tenham sido os pontualmente pelo contribuinte, razão $\imath$ qual o texto legal refere-se, apenas, aos ídos subseqüentes e assim não existiria rapara negar ao contribuinte o direito de, bém, compensar dívidas tributárias, corondentes a períodos anteriores ao recolhito por erro, ou à data da reforma, anula, revogação ou rescisão da decisão denatória, desconstituída, revogada, anulasu reformada.

Invoca Cassone para tanto, os artigos 1.009 Código Civil e o artigo 66 da própria Le 8.383 , recomendando, porém, um exame tadoso em cada caso.
3. O direito do contribuinte à compensação, constituído o suporte fático descrito na lei, constitui-se em direito subjetivo e é autoexecutável, não havendo necessidade de qualquer autorização do Poder Executivo a respeito e quaisquer normas baixadas pelas administração pública serão ineficazes se visarem obstaculizar ou, se de fato, vierem obstaculizar, a compensação tributária.

4. $O \$ 1^{\circ}$ do artigo 66 admite a compens ção entre tributos e contribuições da mesma espécie.

A respeito, formaram-se 2 (duas) correntes a saber:

4.1. Entendem alguns que a compensação prevista no $\$ 1^{\circ}$ do artigo 66 não permite que diversos impostos ou contribuições ou taxas federais possam ser compensados entre si; teria permitido a lei, apenas, por exemplo, a com pensação de imposto de renda pago com imposto de renda a pagar, de imposto sobre importação pago com imposto sobre a importação a pagar, Cofins com Cofinis, Finsocial com Finsocial, impondo ao contribuinte uma limitação que parece injustificável, considerandose especialmente a "identidade da caixa" ou a "Kassenidentität" já, que, o destinatário de todos os tributos e contribuições federais é a própria União Federal.

Neste sentido João Francisco Bianco ${ }^{16} \mathrm{e}$ Hugo de Brito Machado ${ }^{17}$, que concluem que a mesma espécie deve ser entendida "como a mesma destinação orçamentária".

4.2. Vittorio Cassone ${ }^{18}$ comenta este entendimento no seu trabalho já citado e diverge desta opinião com muito acuidade jurídica nos seguintes termos:

"Alguns entendem que a compensação somente pode operar-se entre tributos da mesma identidade: IR com IR, IPI com IPI, FINSOCIAL com FINSOCIAL, COFINS com COFINS, e assim por diante. Outros entendem que qualquer recolhimento indevido ou maior do que o devido pode ser compensado com quaisquer outras espécies tributárias da União, inclusive contribuições. 
Não comungo com nenhuma dessas opiniões. Em primeiro lugar, deve-se obedecer à lei $\left(\mathrm{CF}\right.$, art. $\left.5^{\circ} / \mathrm{II}\right)$. A Lei diz que a compensação só poderá ser efetuada entre tributos e contribuições "da mesma espécie". As espécies tributárias estão relacionadas no capítulo do Sistema Tributário Nacional (arts. 145/162); Impostos, Taxas, Contribuições de Melhoria, Empréstimos compulsórios e Contribuições sociais.

Se é a própria Constituição que diz quais são as espécies tributárias, e sobrevém a Lei para permitir a compensação entre tributos e contribuições da mesma espécie, não vejo como possa dar-se outra interpretação senão aquela segundo a qual impostos podem (e devem) ser compensados com impostos, taxas podem ser compensadas com taxas, contribuições sociais podem ser compensadas com contribuições sociais. E a lei $\left(\$ 1^{\circ}\right)$ andou bem em assim dispor.

Com efeito, não é possível compensar impostos com contribuições sociais, porque enquanto aqueles são arrecadados para custearem despesas gerais, sendo proibida a vinculação da receita de impostos a órgãos, fundo ou despesa (art. 167/IV da CF), as contribuições sociais servem para financiar a Seguridade Social (arts. 149 c/c 194/204 da $\mathrm{CF}$ ), e que se acham correlacionados com os três orçamentos que a Constituição determinou e que não se confundem, porque distintos: a) orçamento fiscal; b) orçamento de investimentos; c) orçamento da seguridade social (art. $165 / 5^{\circ}$ ).

Por isso mesmo - e dentro da interpretação sistemática que dou ao dispositivo legal em análise - um determinado imposto pode ser compensado com o mesmo ou com ou tros impostos, porque a natureza destinatária (da sua receita) é a mesma, pertence ao mesmo orçamento (fiscal, da União), dando-se uma sintonia, uma harmonia, uma perfeita correspondência entre ambos, adequase o art. 1.009 do CCB c/c art. 109 do CTN, com base fundamental nos arts. 146 e $5^{\circ} / \mathrm{I}$ da $\mathrm{CF}$, portanto, não só do ponto de vista jurídico, como também sob o aspecto lógico e contábil-financeiro. Na mesma linha de raciocínio, o FINSOCIAL pode ser compensado com o COFINS, porque pertencem à mesma espécie tributária (contribuição social para a Seguridade Social) e ao mesmo tempo orçamento, o que significa dizer que contêm todos os requisitos e condições para compensarem-se."

Entendem os autores que se filiam à mesma opinião de Cassone que, se assim não for, poderá a Administração Pública Federal criar, através de normas infralegais, subespécies de impostos e contribuições e assim obstaculizar ou dificultar a compensação de impostos ou contribuições, apesar de serem da mesma espécie, ou como mostra o Professor Alcides Jorge Costa a respeito da Instrução Normativa 67 , se a receita estabelecer um código para um tipo de rendimento de pessoa física e outro para o outro tipo de rendimento da mesma pessoa física, ambas as incidências não servem mais do mesmo imposto, e, conseqüentemente, não seria possível sua compensação no direito tributário brasileiro.

5. Examinando-se o texto do artigo 66 da lei 8.383, impõe-se a conclusão que o mesmo, combinado com os artigos 1009 e 1010 do Código Civil permite, na área federal, ao contribuinte, optar pela compensação legal através do exercício do direito formativo extintivo, não cabendo à Administração Pública estabelecer quaisquer outras exigências ou normas infralegais para a plena existência, validade ou eficácia da compensação.

6. $\mathrm{O}$ artigo $66, \$ 2^{\circ}$ da lei 8.383 permite, ainda, expressamente, ao contribuinte optar entre a compensação ou a restituição (repetição do indébito, nos termos do disposto no artigo 165 do CTN) ("Se o pagamento foi feito além dos limites determinados na fiscal ou o tributo pago não corresponde orevisão legal, surge o indébito tributá,) 19

7. $O \lessgtr 3^{\circ}$ do artigo 66 determina que os lores, objeto de compensação ou de restiição, serão corrigidos monetariamente $\mathrm{m}$ base na variação da UFIR, generalizan,-se, assim, por lei aquilo que o Poder Juciário através da jurisprudência já tinha ssado a conceder nos casos concretos subetidos à seu julgamento.

7.1. O entendimento da Receita Federal, insubstanciado no art. 6 da I.N. 67 que os lores pagos indevidamente à União, antes :1.1. de 1992, apenas sejam convertidos em FIR pelo valor desta em 2 de janeiro de 392, além de não ter qualquer base legal, snstitui-se num verdadeiro acinte ao prinpio da eqüidade, base não apenas do direi, privado, mas também do direito público, I menos do Estado Democrático.

8. Das Normas Infralegais

8.1. $O \int 4^{\circ}$ do artigo 66 da lei $8.383 \mathrm{faz}$ eferência a instruções a serem baixadas pala eceita Federal e o Instituto Nacional do Seuro Social, o que efetivamente ocorreu pela ustrução Normativa $n^{\circ}$ 67, de 26.05.92, exedido pelo Diretor do Departamento da Reeita Federal - D.O.U. de 27.05.92 e pela Seretaria da Previdência Social o Ministério, través da Orientação Normativa $n^{\circ} 2$, de 1.08.94 D.O.U. de 15.08.94

8.2. Foi solicitado, ainda, parecer à Prouradoria-Geral da Fazenda Nacional 'G.F.N./CRJN, que tomou o n ${ }^{\circ} 638 / 93$, tinente à correta interpretação do artigo 86 la lei 8.383 , tendo esse sido publicado no Siário Oficial da União de 29.07.93. Este arecer adota a mais restrita interpretação maginável a respeito, e apoiando-se no art. $t^{\circ}$ do C.T.N. (A natureza jurídica de um :ributo é determinado por seu fato gerador), intende o parecista, que tributos da mesm espécie são os que tem o mesmo fato gerador. Merecem ainda destaque as seguintes conclusões constantes do referido parecer.
8.2.1. Não se pode dar à compensação de créditos tributários tratamento jurídico igual ao dispensado à compensação de créditos comerciais e civis, uma vez que as normas aplicáveis aos tributos, inclusive ao indébito tributário, atendem ao regime de Direito Público, o que afasta o regime de Direito Privado, também, no que tange à compensação.

8.2.2. A principal diferença entre a compensação do Direito Privado e a do Direito Tributário é que esta pode ocorrer somente na hipótese de existir lei específica do ente titular da competência tributária, autorizan do a autoridade fiscal competente a proceder à compensação entre créditos fiscais com créditos do sujeito passivo contra o Fisco, observadas as condições e garantias por essa lei específica estipuladas, ou estipulações, caso a caso, atribuídas por ela à autoridade administrativa.

8.2.3. O sujeito passivo da obrigação tributária não tem, em princípio, direito subjetivo à compensação, sendo. que esta não é obrigatória nem se opera automaticamente. Para ter direito à compensação, não basta o contribuinte entender que pagou ou recolheu o tributo ou a contribuição federal indevidamente, ou a mais que o devido, sendo necessário que o seu respectivo crédito tenha sido reconhecido pela Administração Fazendária ou por decisão judicial com trânsito em julgado, eis que o art. 170 do CTN assim o exige, para que seja possível a compensação, e ainda que o crédito do sujeito passivo contra o Fisco seja líquido e certo.

8.2.4. Apesar da própria IN 67/92 permitir diretamente ao contribuinte a compensação de débitos vencidos a partir de 01.01.92, afirma ainda o parecerista que o contribuinte não pode pretender a compensação de créditos de tributos e contribuições, devendo esses seguir o regime especial do Direito Público. Assim, a compensação somente pode ser realizada na hipótese de autorização específica de lei e em estrita obediência às condições e às garantias estipuladas 
por essa lei especial e por ato regulamentar $\mathrm{da}$ autoridade fazendária;

\section{Em conclusão}

1. A doutrina e a legislação resistiram po muito tempo à admissão da compensação no direito tributário, ou negando-a simplesmente, ou admitindo-a, apenas, com vastas restrições;

2. O Código Tributário Nacional, Lei Complementar, a admite nos termos do disposto no seu artigo 170, parágrafo único mas, ainda, exige para sua concretização, lei ordinária específica;

3. $\mathrm{Na}$ área federal, foram promulgadas diversas normas legais ordinárias, especialmente as consubstanciadas no artigo $66 \mathrm{~d}$ lei $\mathrm{n}^{\circ} 8.383$ de 30 de dezembro de 1991 atinentes, apenas, à compensação de tributos federais.

Mesmo essas normas, entretanto, carac terizam-se pelas restrições, que ao menos aparentemente contém, quanto à compensação, comparando-as, por exemplo, com as normas correspondentes do Código Tributário Alemão; $\mathrm{e}$

4. Tendo surgido sérias divergências, quanto à sua interpretação em relação à sua aplicabilidade temporal e quanto aos tributos que possam ser compensados entre si, caberá ao Poder Executivo reformular as normas ou ao Poder Judiciário, quando de sua aplicação ao caso concreto, dar-lhes interpretação, de acordo com o sistema jurídico brasileiro.

5. São gritantes as restrições constantes das normas infralegais baixadas pelos órgãos do Poder Executivo, quanto à execução da lei $n^{\circ} 8.383$, afrontando a legislação específica.

\section{Observações finais}

A conquista do direito subjetivo público quanto à compensação de crédito do contri- buinte contra o Estado por créditos tributários do Estado contra o contribuinte, faz parte da luta pela conquista da cidadania e da democracia, da luta do homem contra o Estado;

Na primeira e na segunda metade do século XX, mentes brilhantes, juristas, notoriamente insuspeitos de qualquer interesse subalterno, negam esta possibilidade por " $\mathrm{ra}$ zões de Estado", para resguardar o Estado, prejudicando o mais legítimo interesse do contribuinte de recuperar o que pagou po erro ou que lhe foi exigido pelo Poder Público contrariamente à lei.

A própria ordem jurídica privada através de seus Códigos Civis esforça-se, ainda em dificultar a obtenção pelo cidadão daquilo que lhe é devido pelo Poder Público.

Mas a humanidade avança e com ela a idéia da democracia, a idéia da igualdade e a idéia do direito subjetivo público.

Devagar surgem leis novas a respeito, os códigos mudam; o mundo não aceita prepotência do Estado e de repente a ordem jurídica cria instrumentos que permitem ao cidadão compensar com o Estado os seus créditos e suas dívidas.

Rudolf von Thering escreveu na sua magnífica obra "A Luta pelo Direito" que não existe no mundo qualquer direito subjetivo que não tenha sido arduamente conquistado por alguém.

A conquista da liberdade e da igualdade pelos povos decorre de uma luta de gerações.

A conquista da compensação também foi, é e será, o resultado de uma luta, que ainda não terminou, mas a aurora do dia da vitória já se anuncia no horizonte.

\section{Notas}

1 Pontes de Miranda, Tratado de Direito Privado, vol. 24, p. 305, $2^{2}$ edição, 1959, Editora Borsoi.

2 Edouard Cuq, Les institutions juridiques des romains, Paris, 1902, apud Maria Helena Diniz, Curso de Direito Civil Brasileiro - $2^{\circ}$ volume, Teoria Geral das Obrigações, 1991, Editora Saraiva, p. 250. 'ontes de Miranda, obra já citada, pág. 331. Jiniz, Maria Helena, obra já citada pág. 252 'ontes de Miranda, obra já citada, pág. 326. ontes de Mranda, obra já citada, pag. 326. 1pud Código Civil de La República Argentina, Ed tor P. de Zavala - Buenos Aires, pág. 197. Texto utilizado é o da tradução feita por Souza niz, Distribuidora Record, Rio de Janeiro, 1960. Münchener Kommentar, Bürgerliches Gesetzbuch, huldrecht Allgemeiner Teil, 2. Auflage-Verlag, C.H. ck, pág. 1228.

O texto usado é o da Tradução de Alfred J. Schmid, andão Machado, Eduardo Frederico de A. Carvalho, ard W. Rothamn, Henry Tilbery e Ruy Barbosa No eira publicada em co-edição do Instituto Brasileiro Direito Triburário e pela Cia. Editora Forense, 1976. A posibilida de compensar créliros vincendos A possibilidade de compensar crédtos vincendos Cón Codigo Civil apenas, admite a compensação de crédi-

1 Ricardo Mariz de Oliveira e João Francisco Bianco, mposto de Renda Lei n' ${ }^{\circ} 8.383 / 91^{\prime}$, Malheiros, São aulo, 1992, pág. 90

Hugo de Brito Machado, "Curso de Direito Triburio", $9^{2}$ ed., Malheiros, São Paulo, 1994, pág. 142. ; Vittorio Cassone, L.T.R. - Suplemento Tributário $1 / 93$.

SObra já citada, pág. 91.

7 Obra já citada, pág. 143

8 Publicação já citada.

9 Ricardo Moniz de Oliveira e João Francisco Bianco, bra já citada, pág. 88.

\section{Bibliografia}

bgabenordnung, Klein Orlopp, Verlag C.H. Beck lünchen, 1989

aleeiro, Aliomar. Direito Tributário Brasileiro, 10. ed., io: Forense, 1981

oletins IOB $n^{\circ} 32$ e $n^{\circ} 33$ - Imposto de Renda e Legi ifão Societária.

\section{Porto Alegre, março de 1995}

\section{Notas}

N.B. 1 - Este trabalho foi elaborado antes do advento da Lei $n^{\circ} 9.250$ de $26 / 12 / 1995$, cujo urigo 39 incide sobre a matéria com finalidade claramente restritiva.

2- Merece destaque, quanto à atualização da matéria, o trabalho "Compensação de Valores Pagos a Maior ou Indevidamente”, publicado pela IOB - Imposto de Renda e Legislação Societária, Ano XXX, 4ª Semana de Maio de 1996, Nr. 21, páginas 259 a 252. 